\title{
Exploring Students' Perceptions of ESL Writing
}

\author{
Dr Sadiq Abdulwahed Ahmed Ismail \\ Faculty of Education \\ United Arab Emirates University \\ P.O. Box 17551, Al-Ain, United Arab Emirates University \\ Tel: 97-150-449-7088 E-mail: Ism232@yahoo.com
}

Received: August 24, 2010 Accepted: October 19, 2010 doi:10.5539/elt.v4n2p73

\begin{abstract}
Writing has always been regarded as playing a prominent role in learning a second language. Research within this discipline has mainly focused on the development of writing skill, but in recent years, some researchers have examined students' perceptions of writing. The purpose of this study was to investigate students' perceptions about an academic writing course and writing in general. A total of 64 female students from an ESP program participated in the study. The general design of the study was quantitative and qualitative in nature as a questionnaire and a focus-group interview were implemented for data collection. A combination of quantitative and qualitative procedures was employed to analyze the data collected via the questionnaire and the focus group interview respectively. The overall results demonstrated the students' positive views towards the Academic Writing Course (AWC) in particular and ESL writing in general. The major findings demonstrated students' awareness of their needs and ESL writing requirements. The study concluded with recommendations for future research.
\end{abstract}

Keywords: Skill, Writing, Course, View, Text, Academic

\section{Introduction}

Writing has always been seen as an important skill in ESL classes. It is the area in which learners are expected to be offered adequate time to develop their writing skill. Writing is certainly an important element of learning English as a second language. This importance is eventually derived from the fact that it reinforces grammatical structures, vocabulary and idioms that we have been teaching to our students. Writing should receive more attention in ESL classes in order to prepare learners to cope with the communicative demands of real life situations. Undoubtedly, the purpose of teaching writing skill is to prepare ESL learners to become better writers. Exposing them to the writing process itself is then a better way for achieving this goal. Writing skills can be developed when the learners' interests are recognized and when they are exposed to situations where they can produce authentic piece of writing. One of the goals of ESL students is to learn to produce a well-structured piece of writing which is recognized and accepted in their academic departments. Consequently, a writing program is expected to be structured in a specific way to meet the expectations and needs of the learners. After surveying the literature, it was found that a number of researchers addressed the need for ESL students to be exposed to a variety of genres (Hinkel, 2004; Hyland, 2004; Ferris and Hedgcock, 2005). The AWC course was found to mainly address classroom genres such as compare and contrast, cause and effect, and problem-solution, but it neglected writing for occupational purposes such as helping students to develop competence in the specific genres that can assist them in their academic study, workplace and their lives in general.

Writing is really seen as a process of discovery as the writers try to find their way while they are struggling to think, compose and put their ideas together. In that way, it is not looked at as a static process but as a cognitive, social and dynamic one. In their study to investigate the cognitive effort of students while writing, Olive, Favart, Beauvais and Beauvais (2009) found that the cognitive effort interacted with genres. They indicated that students' cognitive writing effort decreased or increased when they were writing certain types of texts such as argumentative and narrative texts. During the process of writing you may discover an idea which is new to you and you have never thought of before. Zamel (1983) argued that writers discover and formulate ideas as they go through the process of writing. Thus, a genuine writing task should place a learner in situations that require authentic use of language to communicate. The ESP program within the United Arab Emirates University (UAEU) tries in part to prepare students to cope with such demands. Those students are expected to be able to produce an acceptable academic text by the time they start their academic courses in their colleges. However, many of them are found to fail to meet their colleges' requirements in producing an appropriate piece of writing which is both linguistically and 
communicatively valued by academic departments. Thus, exploring students' needs and perceptions will eventually lead to offer the right assistance. Extending the line of previous research, this study investigated the students' perceptions and views of an academic writing course.

\section{Problem Statement}

Writing was seen as the most challenging skill for a significant number of UAEU's students who were studying ESP courses as part of the requirements of the undergraduate programs. Even after successfully finishing the ESP courses, a number of those students were found to fail to meet their colleges' requirements in producing an appropriate piece of writing which is both linguistically and communicatively valued by academic departments across the University. Many of those students came to the ESP program with different levels of language proficiency, different learning styles, different assumptions about writing and different views about the AWC course. Therefore, it was extremely important to understand what the students were bringing with them to the program in order to be able to respond appropriately to such demands when structuring and executing the program. Hence, the main objective of the present study was to investigate students' perceptions of writing, learning styles, writing ability and the AWC course which had become a general writing course rather than an ESP course.

\section{Research Questions}

a. How do students perceive writing in English?

b. How do students perceive their favorite learning style?

c. How do students view their writing ability in English?

d. How do students view the new Academic Writing course (AWC)?

\section{Literature Review}

Beliefs about ESL writing instruction have always been changing and they are influenced by both first language writing pedagogy and ESL research findings. Hedgcock (2005) stated that there has been a substantial shift in ESL writing toward the implementation of the process approach in teaching writing. This method emerged as a reaction to the traditional approach which was mainly employed to reinforce oral patterns and grammatical knowledge. There are different examples of writing approaches which are believed to offer beneficial frameworks of instruction for the development of writing skill such as writing across the curriculum which tries to integrate writing assignments throughout content areas. Myhill and Locke (2007) revealed that the writing discipline research was classified in a variety of ways by different people. Hyland (2002), for example, outlined three concrete different approaches to writing. The first approach was referred to as a "text-oriented" and was described to deal in different ways with the product of writing. The second one was seen as a "writer-oriented" and was described as a way of dealing with the cognitive process and self-expression. The third one was described as a "reader-oriented" approach and it emphasized the role of the writer as both an active reader and writer.

Writing in the mother tongue is painful for many students, but when it comes to writing in the second language the students' hardship and pain are worsen (Gilmore, 2009). Huang (2008) investigated if there were differences between the rating variability and reliability of ESL students and native English students' writing scores in the provincial English examinations in Canada. The researcher reported differences in scores between ESL and native English students. This result supported the idea that ESL writers might encounter certain hardship when attempting to write in English. Within the discipline of comparing L1 with L2, Kobayashi and Rinnert (2008) examined the effects of intensive preparatory high school training in L1 and L2 essay writing for university entrance exams. It was found that the interaction between L1 and L2 training indicated that the students tended to use the acquired knowledge in their L1 and L2 essay writing. The researchers concluded that writing strategies and competence might be transferred across languages. The hardship that ESL writers may face when writing in English may partially be reduced when the learners effectively employ L1 strategies.

Students usually bring their assumptions and beliefs about what a writing course should offer them and in what way. One of the main objectives of ESP teaching is to provide students with ample of opportunities to practice and learn how to write an academic piece of text that is valued and accepted in their specific disciplines. When taking an academic writing course, students' main purpose is to learn to write effectively within their particular discipline and to succeed in their academic studies. Hence, students' needs, perceptions and present writing proficiency levels should be sought first in order to offer them the required assistance. Research on students' perceptions and beliefs has revealed that knowing students' perceptions and beliefs can play a crucial role in developing the right program to meet their needs. Mazdayasna and Tahririan (2008) found that Iranian students were aware of their needs as they indicated that they were very much interested in improving their general language proficiency to succeed in their academic study. They concluded that there was not good coordination or communication with the relevant academic 
departments about the students' real needs. They attributed the inefficiency of the course to the absence of the need analysis process and the lack of communication and coordination between different parties. However, other variables, which had not been accounted for, might also have contributed to the negative results of the course.

Like other ESL learners, ESP students have their own attitudes and perceptions about the feedback they receive about their writing. Lee (2008) stated that the classroom context may play a vital role on the students' perceptions of teacher's feedback. Students may perceive feedback either as an effective or negative indicator of their learning. Hyland and Hyland (2006) and Lantolf and Pavlenko (2001) argued that learners are always viewed as active participants who view all comments about their work as valuable, useful and helpful for their writing. Students are always positive about receiving teacher's feedback on their writing accuracy as they are eager to have their mistakes highlighted by the teacher. Studies carried out in the area of students' perceptions and preferences of the kinds of feedback, demonstrated that students possess very strong views about the types and amount of feedback offered by their teachers (Ferris, 1995; Montgomery and Baker, 2007).

Recently, a number of researchers have examined the forms and purposes of feedback as well as its impact on the students' written work. The effects of feedback depend largely on the kinds of feedback provided by the teacher, students' proficiency, students' educational and cultural background and expectations. Results from research revealed that feedback was found sometimes helpful but at other times it was found to prevent or not to have any kinds of impact on students' learning (Silva and Brice, 2004; Hedgcock, 2005). Both teachers and students believe that feedback is indispensable throughout the writing process. Montgomery and Baker (2007) pointed out that teachers are aware throughout the writing process of their students' perceptions of feedback and they try effectively to provide them with constructive and encouraging feedback. In their study about peer review, Lundstrom and Baker (2009) conducted an investigation to find out whether giving feedback or receiving feedback can contribute more to improve student-writing skill. Students from an intensive English program were divided into "givers" and "receivers". The overall results showed that the "givers", who looked at other students' writing, made a considerable progress in improving their own writing during the semester. Nevertheless, this idea of 'givers' and 'receivers' will probably achieve its most fruitful objective if the trainee writers share the same cultural and educational background.

Kobayashi and Rinnert, (2002) highlighted the salient points about ESL/EFL learners who come from the same L1 educational background. They indicated that even students who share the same mother tongue may have completely different schooling background. It is, therefore, crucial to find out about the students' literacy background and previous training. Consequently, they advocated their study to find information about students' L1 literacy as that is extremely important for teachers who need to help their students improve their writing skill in L2. Following the same bath, Griffiths (2007) investigated teachers' and students' perceptions about the importance of using learning strategies. The findings highlighted that teachers might enhance those important strategies employed by their students. Students usually bring with them to the ESL writing class the whole culture of L1 education including the cultural patterns of L1 writing which may influence L2 writing. This issue of contrastive rhetoric has been addressed in the literature to contribute positively in the development of second language writing pedagogy (Connor, 1996). Yet, this traditional rhetorical pattern was criticized and seen as a static pattern that always views the learners drawing on their past culture and experience rather than moving forward and taking an active role in learning (Leki, 2000; Kobayashi and Rinnert, 2002). In a study about culture, beliefs and identity, Xuemei (2007) investigated the construction of the writers' identity and the development of their beliefs in an ESL context. The findings indicated that culture, identity and beliefs interacted together to reconstruct the learners' beliefs and identity on the basis of writing in particular and education in general. Thus, students' beliefs might be partially demonstrated by the kinds of strategies they employed when writing.

Recently, language learning strategies have been the focus of some research in different parts of the globe. As a result of believing that strategies are central for assisting ESL learners to enhance their writing abilities, a number of studies were conducted to explore writing strategies and their benefits (Cohen and Brooks-Carson, 2001; Casanave, 2002; Sasaki, 2007; Roca de Larios, Manchon, Murphy and Martin, 2008; Fenghua and Hongxin, 2010). Strategies are broken down into three different categories according to whether they are cognitive, social, affective or metacognitive (Cohen, 1998). This categorization appears to be the most widely used framework for categorizing and studying strategies used to learn certain skills. After differentiating between language learning strategies and language use strategy, Cohen (1998) used "language learner strategies" to refer to both of them. Zhang and Goh (2006) indicated that the first set of strategies refers to the conscious actions taken by the second language learners to develop the process of learning while the second one refers to those strategies being used to improve the use of the target language. In a study to explore EFL learners' writing strategies used within the 'Activity Theory' framework, Xiao (2008) focused on how two learners used certain strategies to mediate their writing process. In a similar study, Riazi (2008) investigated the perceptions of strategy-use among Arab students in a university in Qatar. Both studies 
argued in favor of the positive role that strategies may play in the process of learning writing. Within the context of Saudi Arabia, Al-Hazmi (2006) looked at students' perceptions of the writing process through providing them with opportunities to continuously reflect on what they were doing. His main intention was to promote the writing class into a personal learning experience through continuous reflection and critical thinking. However, the overdependence on an open ended questionnaire did not enable the researcher to capture the larger picture of the writing process.

The issue whether second language student writers attempt to think directly through the second language (L2) or through translating from the first language (L1) while composing a text generated some interesting research (Weijen et al., 2009; Wang and Wen 2002; Cohen and Brooks-Carson, 2001). Cohen and Brooks-Carson (2001) investigated whether thinking through L1 and even writing out a text first in the L1 may actually enhance the production of good writing in L2. They concluded that writing directly in the second language may attract some learners when they are working under time pressure. In their study, Wang and Wen (2002) confirmed that the L2 writing process is a bilingual event since the second language writers have two languages (L1 and L2) at their disposal when they are attempting to compose a text in L2. However, the central problem is that it is not clear how the use of L1 is related to the occurrence of different cognitive activities in second language writing, such as planning and generating ideas. The reason behind first language use and the type of cognitive activity employed while writing is still not clear. Students participated in the present study have a language (Arabic) which is written from right to left with different scripts. When trying to use L1 writing strategies, students may need to carry out different cognitive activities to adjust those strategies to the norm of writing in L2. Thus, learners' L1 experience and knowledge can play a significant role in the development of L2 writing skill.

\section{Methodology}

\subsection{Subjects}

The participants of this study were 64 female ESP students enrolled in four sections in the AWC Course in the ESP Program, UAEU. The first two sections included thirty-two students enrolled in different departments in the College of Humanities and Social Sciences while the second two sections included also thirty-two students enrolled in the College of Education. At the time of conducting the study, all students started taking academic courses in their colleges after they had finished and passed all university requirements courses and had also scored at least 4.5 in the IELTS exam. All these students followed the same AWC course although they belonged to different colleges and different majors within each college. The level of most of these students can be classified as pre-intermediate. The above mentioned four sections were randomly assigned by the ESP program to be taught by the researcher who was teaching there at the time of conducting the research. The equal numbers of students in each section were determined by the program ceiling of 16 students in each section. Students were not placed in ESP sections according to any kinds of criteria such as the results of a placement test, but they were allowed to register randomly in any section until it was full.

\subsection{Instruments}

Two major tools were employed to collect data from the target classes. A twenty-eight items questionnaire was developed in accordance with the research questions to collect the intended data. All the items were grouped and put into four categories to meet the structural requirements of the research questions. The questionnaire was reviewed and referred by a number of university instructors. Later, it was piloted with thirty-two students. The final version of the questionnaire was reviewed and structured in accordance with the referees' comments and the piloting results. Hence, the final draft of the survey included twenty eight questions of a five point Likart scale descending from " 5 " as strongly agree to "1" as strongly disagree. An open ended question was placed in a separate sheet to give participants chance to express their opinion freely regarding what they liked and disliked about writing in English. Using Cronbach Alpha Formula, the reliability of the questionnaire was found to be 0.92

The focus group interview technique included nine questions intended to consolidate the data collected via the questionnaire. These questions were not rigid in nature but they were flexible and allowed the participants to think and express their own answers freely. They were also checked by a panel of instructors in the UAEU to find out if they were consistent with the data that was intended to be gathered via the questionnaire. Interview sessions were organized during class time and office hour time. Special interview sessions before the early morning classes were organized for some students who could not join the office hour sessions and for those who showed enthusiasm to attend more sessions.

\subsection{Data Collection}

The researcher started collecting the data during the eleventh week of the first semester of the academic year 
2007-2008. Data collection was planned and scheduled to take place at that particular time in order to allow adequate time for students to gain more experience about the course and to allow the researcher who was the teacher of the writing course at that time to establish good rapport with the students. Also, by that time, it was guaranteed that students would definitely have sufficient experience and knowledge about the content of the AWC writing course. Sixty four questionnaires were distributed and recollected from all students during class time. The focus group interviews lasted for almost the remaining time of the semester. In each section a number of students were grouped together and interviewed either during their classes or by setting an appointment during office hour time. Special sessions were organized for those students who could not come to office-hour sessions and those who expressed interests in continuing to participate in the discussion.

\subsection{Data Analysis}

Both qualitative and quantitative techniques were employed for the purpose of analyzing the data. The SPSS program was used to obtain different types of descriptive statistics and independent sample $t$-tests from the quantitative data collected via the questionnaire. A Qualitative data analysis technique was used to look at the data collected via the focus group interviews. A framework was created to categorize the data into themes (Denzin and Lincoln, 1994). Following Creswell (2003) the interpretation of the quantitative five scale Likert questionnaire data was supported by the qualitative data obtained via the focus group interview to compare and contrast the students' perceptions about writing. Thus, students' comments and views from the focus group interviews were incorporated with the discussion of results obtain from the questionnaire for each research question where appropriate. The analysis focused on the similarities and differences in the views of both Education and Humanities' students. The findings of the questionnaire were looked at and analyzed in the same sequence as the four research questions were posed earlier.

\section{Results and Discussion}

When looking at the results of the first research question (How do students perceive writing in English?), we find out that the overall mean score for both Humanities and Education ranged from 3.25 to 4.52 on a 5 point scale descending from strongly agree " 5 " to strongly disagree " 1 " (see table \#1). The overall mean indicated that students had high perceptions about the importance of ESL writing skill for their academic study and their future career. This particular result asserted that ESP students were aware of their needs to improve their writing proficiency in English. This result was in accordance with a study carried out by Mazdayasna and Tahririan (2008) about the EFL needs of Iranian undergraduate students in both the College of Nursing and the College of Midwifery. Their findings indicated that the ESP students were aware of their needs and the requirements to improve their general language proficiency. Similarly, in their study about the benefit of corpus-use in second language writing, Yoon and Hirvela (2004) found that students were positive about the use of corpus in L2 writing. Students stated that the use of corpus helped them acquire patterns of words and enhance their writing skill. This result affirmed that students were aware of their learning and could easily judge the usefulness of the used materials and activities.

The results showed that there were sometimes big differences between Humanities and Education students. In some cases, Humanities students had sometimes higher perception mean scores than Education students such as their mean score for the variable related to the 'future needs of writing'. The mean scores for this variable were 4.78 and 3.78 for Humanities and Education respectively. This significant difference might be explained within the context of students' specific specialties in their disciplines. Students in the College of Humanities were enrolled in different disciplines some of which were to some extent not in harmony with the job market. Students in those disciplines needed to learn particular skills such as English in order to compete in the local job-market. However, a number of students in the College of Education might feel that writing was not important for them as they would mainly become teachers and Arabic is the medium of instruction for most courses in government schools. Another likely interpretation is that many of the Humanities students in those ESP sections were enrolled in English medium departments such as Literature, TESOL, Linguistic and Translation. During the focus group interview a number of Humanities students indicated that they were enrolled in English studies departments where they had to do intensive and extensive writing. However, only a few Education students indicated that they needed to improve their writing proficiency as they were specializing in English and they might be involved in teaching English in the future. The focus group interviews provided the students with ample opportunities to think and reflect on their language learning needs and experience. This point is in accordance with Al-Hazmi's (2006) study final statement which confirmed that reflection was an essential element of the learning process as it enabled students to express their thought and evaluate their experience.

The second research question (How do students view their favorite learning styles?) investigated the students' perceptions and awareness of their learning styles. The findings of this question did not show much difference 
between the two groups of students from the two colleges. However, analysis demonstrated a significance difference in the mean score of only one variable. The mean scores for the variable related to students' demand for writing assistance were 3.25 and 4.31 for Humanities and Education respectively (see table \#2). This significance difference as it was indicated by the T-test might be viewed in terms of students' language proficiency and the academic program in which they were enrolled. As it was highlighted before, many students in the College of Humanities were following their academic studies in English medium programs while the majority of Education students were planning to join the teaching profession in government elementary schools where Arabic language is the medium of instruction for most subjects. During the focus group interview, the Humanities students reiterated that they could manage their writing task independently and they might only need a little help from the teacher. Also, during classroom instruction and activities those students showed a high degree of confidence to work autonomously. Many of the Education students, on the other hand, felt more secure and comfortable when working with the teacher. A number of them pointed out that they were always seeking teacher's assistance and they felt comfortable and assured when the teacher checked their written work. In his study about Egyptian high English writing apprehension and low English writing self-efficacy, Abdellatif (2007) reported that ignoring language based writing skills could lead to high writing apprehension. Like Egyptian students the present study's subjects also pointed out that they need to improve their writing proficiency and get rid of their anxiety. They expressed their concerns about making mistakes and how eager they were to see them corrected by the teacher.

Another Interpretation for the big difference in perception about "writing assistance" in favor of the Humanities' students could be based on their view about the AWC textbook. During the focus group interview, some students referred to the textbook as easy, useful, helpful and well organized. They admitted that the book guided them gradually through the process of writing an essay which was their target goal. A similar point in the literature was found in a study conducted by Kobayashi and Rinnert (2002) who investigate high school Japanese-students' perceptions of language literacy instruction. After surveying the perceptions of a large number of Japanese students and a relatively small number of American students, the researchers reported that both groups asserted that dealing with modern essays was their relative target goal. The overall perceptions of Japanese high school students revealed that classes offered relatively more reading-based activities than writing based ones. Additionally, the results from the interview supported the questionnaire's findings that Japanese students have less writing experience. Similarly, during the focus group interview in the present study, the Education students indicated that they were having difficulty in writing in English because they did not have enough experience in the past. Although, students from the College of Humanities pointed out that the AWC was easy for them, their actual written work demonstrated that they still needed to work harder to acquire the basic writing skills. This result is similar to a finding reported by Zhou (2009) about learners' views about improving grammar and vocabulary in their writing for academic purpose. Zhou (ibid) reported that learners were found to be motivated to improve the grammar and vocabulary of their writing but they lacked the strategies to take appropriate action toward the achievement of their goals. Like the subjects of the present study, those students were found to possess false assumptions about their actual language competence. As demonstrated in their writing assignments, the overall writing proficiency of both groups in the present study was not very different. Measuring the writing proficiency of the students was not the target goal of this study but the researcher had the advantage of teaching the AWC course to those students while conducting this study and this issue can be the topic of a future research.

Research question 3 (How do students view their writing ability in English?) dealt with students' perceptions and beliefs about their ESL writing skill. When looking thoroughly at the data for this question, we find that there is not much difference between the mean scores of the Humanities and Education students regarding their beliefs about their ESL writing ability. The overall mean scores ranged from 2.06 to 3.56 while the individual mean scores for both groups ranged from 1.69 to 381 (see table \#3). This result may be interpreted in relation to the students' social and educational background. All these female students were sharing the same social background and they had almost been exposed to the same Educational experience. Nearly everyone went to government schools where a national curriculum and a well established supervision system were carefully and precisely implemented. Kobayashi and Rinnert (2002) indicated that students' writing might be influenced by their writing experience in their first language. They found that both the Japanese and American students spent a lot of time reading and interpreting prose. However, the Japanese students were found to invest less time in writing than their American peers. This result coincided with the questionnaire results which reiterated that Japanese classes were offered more reading based activities and pay less attention to writing activities than American students. This proved that the Japanese ESL students were influenced by the culture of their education which required them to do less writing. Similarly, the ESP students' perceptions about their writing might be influenced by their experience with first language writing.

Another interpretation may be attributed to the students' understanding of the question. The students might interpret 
that the question was asking them to generally reflect on their writing experience. Many of those students were expected to write most of their assignments for other courses using English. In this regard, students indicated during the focus group interview that they conducted other courses' assignments successfully. Students from both groups stated that they got good grades for their assignments in other courses. Their high grades in those courses might have given them the impression that their writing skill was acceptable. Students also revealed that other teachers did not show them any mistakes in their writing and this might have contributed to their false impression about their writing. Hence, students might falsely have concluded that they had already mastered ESL writing.

When looking at the results of each individual variable under this question, we realized that there were a few significance differences. The score means for the students' negative feeling (hating writing) about ESL writing was 1.69 and 2.66 for Humanities and Education students respectively. The Humanities students were realized to be more positive about the ESL writing skill. This difference might be partially related to the language proficiency of both groups. They believed that they were good writers and their answers to that 'opinion question' might have been based on that view. The Education students' judgmental view about the writing skill might be related in the first place to their limited language proficiency. Many of these students were struggling to carry out their writing assignments in class or during exams in order to meet the minimum requirements of the course. Some of the Education students stated that they only hated writing when they were asked to write in every class. Similarly, the mean scores for their feeling toward class writing activities were 2.59 and 3.47 for the Humanities and Education students respectively. The negative view of the Education students might again be attributed to the difficulty that they were facing when participating in a class writing activity. During the focus group interview some of them expressed that they could only enjoy a writing task if they had to do it together like those activities for listening and speaking skills. This result was similar to Storch's (2005) findings about collaborative writing. When students were given the choice to work either in pairs or individually, a number of them chose to work in pairs and produced shorter and better pieces of writing. All students were found to have positive attitude toward pair-work, group-work and collaborative writing in general.

When asked if they were good writers in both Arabic and English, more Education than Humanities students thought that their writing proficiency in both languages was not good. The mean score for this particular variable was 1.84 and 2.31 for Humanities and Education respectively. This might be related to the Education students' language proficiency in general. Those students viewed themselves as inefficient writers in their first language and this might have influenced their ability to develop a proficient writing skill in the second language. His point highlighted the possibility of the influence of the cultural writing patterns of students' first language on their second language writing. This point was in agreement with Spack's (1997) study in which the findings supported the idea that first language experience could shape the way in which students approached learning in the second language. In following the progress of a Japanese student's English writing, Spack (ibid) found that the student was characterizing certain elements according to her first language experience. Later, it was realized that this student became more actively involved in the process of writing and she developed her writing proficiency. The students of the present study might need further training and more exposure to writing in order to develop their proficiency in the same way. Investigating their language proficiency development could be the topic of a future study. Although both groups of students studied in similar government schools, their education background and learning experience might differ in some way or another. In their study about Japanese and American high school students' perceptions about their literacy, Kobayashi and Rinnert (2002) pointed out that we need to be cautious when making generalization about the same group as experiences of individuals might be different. Generalization might only be highlighted after dealing with individual experiences even within the same group.

Research question 4 (How do students view the Academic Writing course?) dealt with the students' perceptions and views about the AWC course. The mean scores for the Humanities group ranged from 2.19 to 3.47 while for the Education group they ranged from 2.47 to 4.03 (see table \#4). The results of this question demonstrated that the Humanities students were a little less positive about the AWC course than the Education students. This might be due to their assumptions about their writing proficiency which was considered from their point of view to be acceptable. Those students might feel that the course was very easy for them and they were not learning very much from it. It might also be attributed to the nature of their program in the College of Humanities where they had to take more advanced writing courses simultaneously. The focus group interview revealed that the Humanities students specifically thought that the AWC course was easy but it included a lot of writing activities. They pointed out that although the AWC was easy, it taught them to plan, organize, edit and finalize their essay. In contrast, some of the results showed that the Education students were a little positive about the course and they thought that they were learning new ideas from it. Like other ESL students, ESP students bring their expectations and views about teaching and learning to the classroom and all their attempts to learn are always guided and influenced by those factors. 
Blanton (1987) stated that the perceptions and views that ESL students brought to the writing class may clash with their ambitions to become proficient writers. Students were always approaching their writing assignments as a test and they did not allow themselves to go gradually through the process of learning to write. Those learners were eagerly looking for the moment when they could master writing and got everything right.

The Result of the 'course attractiveness variable' demonstrated that the Education students had a more positive attitude towards the course than the Humanities students. The mean scores for this specific variable (The AWC is more enjoyable than Level 3 Writing Course) were 3.31 and 4.03 for Humanities and Education respectively. Similarly, the mean scores for the 'AWC usefulness' were 2.91 and 3.75 for Humanities and Education respectively. The positive attitude of the Education students might be attributed to their experience with 'Level 3 Writing Course which was a general writing course. The reason for finding the AWC course more enjoyable than 'Level 3 Writing Course' might be because they felt that the course helped them learn something that they missed in 'Level 3 Writing Course. During the focus group interview, a number of Education students asserted that the AWC taught them for the first time to organize their essay and express their ideas clearly. This result was in agreement with what Storch and Tapper (2009) highlighted in their argument about their students' views about the course. The researchers asserted that EAP programs might positively influence the students' writing and this impact could even be measured quantitatively. They argued that students' comments on the course had always been encouraging and the growing number of students enrolling in the course supported their argument. Also, a study conducted by Leahy (2004) supported the idea that students had always expressed positive view about the course and the course had proved to do its job in preparing the students for their academic study.

As compared with the Humanities group, many of the Education students indicated that they found the AWC less challenging than 'Level 3 Writing Course'. The result of this variable (The AWC is less challenging than Level 3 Writing Course.) asserted what they indicated during the interview and also it confirmed the general assumptions among ESP teachers that Humanities students might find the course more challenging than other students in other disciplines. The mean scores for this variable were 2.81 for Humanities and 3.56 for Education. Though the Humanities students earlier viewed the AWC course as easy, they considered it more challenging when comparing it to Level 3 Writing Course. However, both groups considered the course beneficial as it helped them develop confidence in their writing abilities. Similarly, Yoon and Hirvella (2004) in their investigation about ESL students' attitude toward corpus use in second language writing found that students viewed the use of corpus as beneficial because it assisted them in developing confidence in their writing proficiency.

\section{Recommendations}

The results of this study highlighted certain issues regarding teaching and learning writing in English as a second language. Teachers and educators in similar situations may utilize those results to enhance the teaching and learning of L2 writing. First language influence should be taken into consideration during writing classes as the use of L1 may enhance better writing performance in L2. Students also bring with them to the writing class the whole culture of their education including the cultural patterns of L1 writing which may influence writing in L2. Any decision about writing programs and textbooks should take into account not only students' needs but everything that might affect their learning abilities such as the culture of L1 education in general and the convention of L1 writing in particular. Finally, further studies may assist in investigating and understanding the influence of L1 writing conventions and cognitive activities in boosting L2 writing skills.

\section{Conclusion}

This study explored ESP students' perceptions regarding writing in a second language. The results highlighted the students' expectations and views which they brought with them to the writing class. The findings emphasized the students' positive attitude toward the AWC course and their perceptions of their own ESL writing ability. One of the most important points emerged from the data collected for this study was the students' misconception about their ability'. A number of students expressed that they were satisfied with their present writing skills while in fact they still needed to pay tremendous attention to this particular skill. This point needs to be investigated further in order to find out about the students' actual writing ability and identify the problems that they are facing while writing in English. Another key issue that needs to be looked at is students' meta-cognitive awareness of writing strategies and the actual strategies that they implement while writing. To sum up, the present study made a partial contribution to understand students' views and expectations about ESL writing, so that other studies need to be conducted to carefully investigate issues highlighted by the study such as the ones mentioned above.

\section{References}

Abdellatif, M. (2007). The factors accounting for the Egyptian EFL university students' negative writing affect. Essex Graduate Student Papers in Language and Linguistics, 9, 57-82. 
Al-Hazmi, S. (2006). Writing and reflection: Perceptions of Arab EFL learners. South Asian Language Review, 16(2), 36-52.

Blanton, L. (1987). Reshaping ESL students' perceptions of writing. ELT Journal, 41(1), 112-118.

Casanave, C. P. (2002). Writing games: Multicultural case studies of academic literacy practices in higher education. Mahwah, NJ: Lawrence Erlbaum Associates.

Cohen, A., and Brooks-Carson, A. (2001). Research on direct versus translated writing: Students' strategies and their results. The Modern Language Journal, 85(2), 169-188.

Cohen, A.D. (1998) Strategies in Learning and Using a Second Language. Harlow: Longman.

Connor, U. (1996). Contrastive Rhetoric: Cross cultural aspects of second language writing. New York: Cambridge University Press.

Creswell, J.W. (2003). Research design: Qualitative, quantitative, and mixed methods approaches. Thousand Oaks, CA: Sage Publications.

Denzin, N., and Lincoln, Y. (Eds.). (1994). Handbook of qualitative research. Thousand Oaks, CA: Sage Publications.

Fenghua, L., and Hongxin, C. (2010). A study of metacognitive-strategies-based writing instruction for vocational college students. English Language Teaching, 3(3), 136-144.

Ferris, D., and Hedgcock, J .S. (2005). Teaching ESL composition: Purpose, process, and practice (2nd ed.). Mahwah, NJ: Lawrence Erlbaum Associates.

Ferris, D. (1995). Student reactions to teacher response in multiple-draft composition classrooms. TESOL Quarterly, 29, 33-35.

Gilmore, A. (2009). Using online corpora to develop students' writing skills. ELT Journal, 63(4), 363-372.

Griffiths, C. (2007). Language learning strategies: Students' and teachers' perceptions. ELT Journal, 61(2), 91-99.

Hedgcock, J. (2005). Taking stock of research and pedagogy in L2 writing. In E. Hinkel (Ed.), Handbook of research in second language teaching and learning (pp. 597-613). Mahwah, NJ: Lawrence Erlbaum Associates.

Hinkel, E. (2004). Teaching academic ESL writing: Practical techniques in vocabulary and grammar. Mahwah, NJ: Lawrence Erlbaum Associates.

Huang, J. (2008).How Accurate are ESL students' holistic writing scores on large-scale assessments? A generalizability theory approach. Assessing Writing, 13(3), 201-218.

Hyland, K., and Hyland, F. (2006). Interpersonal aspects of response: Constructing and interpreting teacher written feedback. In K. Hyland and F. Hyland (Eds.), Feedback in ESL writing: Contexts and issues (pp. 206-224). Cambridge: Cambridge University Press.

Hyland, K. (2004). Genre and second language writing. Ann Arbor, MI: University of Michigan Press.

Hyland, K. (2002). Teaching and researching writing. Harlow: Pearson.

Kobayash, H., and Rinnert, C. (2008). Task responses and task construction across L1 and L2 writing. Journal of Second Language Writing, 17(1), 7-29.

Kobayash, H., and Rinnert, C. (2002). High school perceptions of first language literacy instruction: Implications for second language writing. Journal of Second Language Writing, 11(2), 91-116.

Lantolf, J., and Pavlenko, A. (2001). Second Language Activity theory: Understanding second language learners as people. In M. Breen (Ed.), Learner contributions to language learning. (pp.172-182). London: Longman.

Leahy, F. (2004). Proposal for alteration to selection requirements for Master of Information Technology. Faculty of Engineering Report produced for SEPSC 5/07, 20 August 2007.

Lee, I. (2008).Student reactions to teacher feedback in two Hong Kong secondary classrooms. Journal of Second Language Writing, 17(3), 144-164.

Leki, I. (2000). Writing, literacy and applied linguistics. Annual Review of Applied Linguistics, 20, 99-115.

Lundstrom, K., and Baker, W. (2009). To give is better than to receive: The benefits of peer review to the reviewer's own writing. Journal of Second Language Writing, 18(1), 30-43.

Mazdayasna, G., and Tahririan, M. (2008). Developing a profile of the ESP needs of Iranian students: The case of students of nursing and midwifery. Journal of English for Academic Purposes, 7(4), 277-289. 
Montgomery, J., and Baker, W. (2007).Teacher-written feedback: Student perceptions, teacher self-assessment, and actual teacher performance. Journal of Second Language Writing, 16(2), 82-99.

Myhill, D., and Locke, T. (2007). Editorial: Composition in the English literacy classroom. English Teaching: Practice and Critique, Vol. 6(1), 1-10.

Olive, T., Favart, M., Beauvais C., and Beauvais, L. (2009). Children's Cognitive Effort and fluency in writing: Effects of genre and of handwriting automatisation. Learning and Instruction, 19(4), 299-308.

Riazi, A. (2008). Language Learning Strategy Use: Perceptions of Female Arab English Majors. Foreign Language Annals, 40(3), 433-440.

Roca de Larios, J., Manchon, R., Murphy, L., and Martin, J. (2008). The foreign language writer's strategic behavior in the allocation of time to writing processes. Journal of Second Language Writing, 17(1), 30-47.

Sasaki, M. (2007). Effects of study-abroad experiences on EFL writers: A multiple-data analysis. The Modern Language Journal, 91(4), 602-620.

Silva, T., and Brice, C. (2004). Research in teaching writing. Annual Review of Applied Linguistics, 24,70-106.

Spack, R. (1997). The acquisition of academic literacy in a second language: A longitudinal case study. Written communication, 14(1), 3-62.

Storch, N., and Tapper, J. (2009). The impact of an EAP course on postgraduate writing. Journal of English for Academic Purposes, 8(3), 207-223.

Storch, N. (2005). Collaborative writing: Product, process and students' reflections. Journal of Second Language Writing, 14(3), 153-173.

Wang, W., \& Wen, Q. (2002). L1 use in the L2 composing process: An exploratory study of 16 Chinese EFL writers. Journal of Second Language Writing, 11(3), 225-246.

Weijen, D. et al. (2009). L1 use during L2 writing: An empirical study of a complex phenomenon. Journal of Second Language Writing 18(4), 235-250.

Xiao, L. (2008). Exploring a sociocultural approach to writing strategy research: Mediated action in writing activities. Journal of Second Language Writing, 17(4), 217-236.

Xuemei, L. (2007). Identities and beliefs in ESL writing: From product to process. TESL Canada Journal, 25(1), 41-64.

Yoon, H., and Hirvela, A. (2004). ESL student attitudes toward corpus use in L2 writing. Journal of Second Language Writing, 13(4), 257-283.

Zamel, V. (1983). The composing processes of advanced ESL students: Six case studies. TESOL Quarterly, 17, $165-187$.

Zhang, D., and Goh, C. (2006). Strategy Knowledge and Perceived Strategy Use: Singaporean students' awareness of listening and speaking strategies. Language Awareness, 15(3), 199-219.

Zhou, A. A. (2009). What adult ESL learners say about improving grammar and vocabulary in their writing for academic purposes. Language Awareness, 18(1), 31-46.

Table 1. Students' perceptions of writing in English

\begin{tabular}{|c|c|c|c|c|}
\hline \multirow{2}{*}{ Variables } & \multirow{2}{*}{$\begin{array}{l}\text { Overall } \\
\text { Mean }\end{array}$} & \multicolumn{2}{|c|}{ Mean } & \multirow{2}{*}{ T-test } \\
\hline & & Edu & Hum & \\
\hline $\begin{array}{l}\text { Learning to write in English is a very important skill for my } \\
\text { academic study at the university. }\end{array}$ & 4.52 & 4.41 & 4.63 & 1.07 \\
\hline $\begin{array}{l}\text { I need to learn to write in English because it is a very important } \\
\text { skill for my future job. }\end{array}$ & 4.28 & 3.78 & 4.78 & $4.33 * * *$ \\
\hline I like to write in English because I am a good writer in Arabic. & 3.25 & 3.34 & 3.16 & .53 \\
\hline I enjoy writing in English. & 4.11 & 3.66 & 4.56 & $3.02 * *$ \\
\hline I feel that I can be a good writer if I practice writing regularly. & 3.95 & 3.91 & 4.00 & 0.30 \\
\hline
\end{tabular}

Note. ${ }^{*} p<0.05 * * p<0.01 * * * p<0.001$ 
Table 2. Students' views of their favorite learning styles

\begin{tabular}{|c|c|c|c|c|}
\hline \multirow{2}{*}{ Variables } & \multirow{2}{*}{$\begin{array}{l}\text { Overall } \\
\text { Mean }\end{array}$} & \multicolumn{2}{|c|}{ Mean } & \multirow{2}{*}{ T-test } \\
\hline & & Edu. & Hum. & \\
\hline I always need help when I write in English. & 3.78 & 4.31 & 3.25 & $3.51 * *$ \\
\hline I prefer to work with the teacher during a writing activity. & 4.20 & 4.50 & 3.91 & 1.92 \\
\hline I can write better when I work with other students. & 3.56 & 3.53 & 3.59 & .15 \\
\hline $\begin{array}{l}\text { I prefer to look at a writing model before I start writing in } \\
\text { English. }\end{array}$ & 3.92 & 4.16 & 3.69 & 1.43 \\
\hline
\end{tabular}

Table 3. Students' views of their writing ability in English

\begin{tabular}{|c|c|c|c|c|}
\hline \multirow{2}{*}{ Variables } & \multirow{2}{*}{$\begin{array}{l}\text { Overall } \\
\text { Mean }\end{array}$} & \multicolumn{2}{|c|}{ Mean } & \multirow{2}{*}{ T-test } \\
\hline & & Edu. & Hum & \\
\hline I would like to learn all language skills except writing. & 3.56 & 3.81 & 3.31 & 1.42 \\
\hline Writing is not very important skill for me. & 2.25 & 2.53 & 1.97 & 1.64 \\
\hline I hate writing in English because I do not know how to write. & 2.17 & 2.66 & 1.69 & $3.81^{* *}$ \\
\hline I do not enjoy writing in English because it is very difficult skill for me. & 2.06 & 1.97 & 2.16 & .57 \\
\hline I cannot write because my English is not very good. & 2.47 & 2.75 & 2.19 & 1.63 \\
\hline I hate writing in English because I had some bad experience in the past. & 2.58 & 2.72 & 2.44 & .81 \\
\hline I get lost when I start writing in English. & 2.47 & 2.78 & 2.16 & 1.86 \\
\hline $\begin{array}{l}\text { I do not practice writing in English because it is not very important for my } \\
\text { academic study. }\end{array}$ & 2.31 & 2.59 & 2.03 & 1.699 \\
\hline I am not a good writer in both Arabic and English. & 2.08 & 2.31 & 1.84 & $2.68^{*}$ \\
\hline I do not feel comfortable during a writing activity. & 3.03 & 3.47 & 2.59 & $2.82 * *$ \\
\hline
\end{tabular}

Table 4. Students' views of the Academic Writing Course (AWC)

\begin{tabular}{|lrrrl|}
\hline \multirow{2}{*}{ Variables } & Overall & \multicolumn{3}{c|}{ Mean } \\
\cline { 3 - 5 } T-test \\
\hline I only write in English during the ESP class. & Mean & Edu & Hum & \\
The ESP writing class is useful for my academic study. & 2.33 & 2.47 & 2.19 & 1.01 \\
I feel that I learn a lot from the ESP writing class. & 3.50 & 3.53 & 3.47 & .18 \\
The AWC textbook helps me write better. & 3.38 & 3.56 & 3.19 & 1.12 \\
I enjoy the ESP Academic Writing Course. & 3.41 & 3.56 & 3.25 & .91 \\
The AWC is a challenging writing course. & 3.30 & 3.50 & 3.09 & 1.16 \\
The AWC is less challenging than Level 3 Writing Course. & 2.89 & 3.28 & 2.50 & $2.11^{*}$ \\
The AWC is more enjoyable than Level 3 Writing Course. & 3.19 & 3.56 & 2.81 & $2.15^{*}$ \\
I feel the AWC helps me improve my writing skill more than Level 3 Writing & 3.67 & 4.03 & 3.31 & $2.50^{*}$ \\
Course. & 3.33 & 3.75 & 2.91 & $2.60^{*}$ \\
\hline
\end{tabular}

